\title{
Evaluation of childhood traumatic experience as a risk factor for alcohol use disorder in adulthood
}

Lan Wang ${ }^{1,2,3}$, Cui-Xia An ${ }^{1,2,3}$, Mei Song ${ }^{1,2,3}$, Na Li ${ }^{1,2,3}$, Yuan-Yuan Gao ${ }^{1,2,3}$, Xiao-Chuan Zhao ${ }^{1,2,3}$, Lu-Lu Yu $u^{1,2,3}$, Yu-Mei Wang ${ }^{1,2,3}$ and Xue-Yi Wang ${ }^{1,2,3^{*}}$ (D)

\begin{abstract}
Background: We aimed to investigate the effect of early-age (prenatal, infant, and childhood) trauma on adulthood alcohol use disorder.

Methods: A total number of 1534 subjects who were born and live in the city of Tangshan were selected. The subjects were divided into three age groups. General demographic data, conditions of the mothers during pregnancy, and condition of the babies at birth, were collected. The diagnosis of alcohol use disorder was based on Structured Clinical Interviews for DSM-IV Axis Disorders (patient version) (SCID). The childhood trauma questionnaire short form (CTQ-SF) [1] and the Lifetime of Experience Questionnaire (LTE-Q) [2] were used to evaluate stress in childhood and adulthood, respectively.
\end{abstract}

Results: Only male subjects were diagnosed with lifelong alcohol abuse and alcohol dependence. There was no statistically significant difference in the prevalence of lifetime alcohol use disorder $\left(X^{2}=4.480, P=0.345\right)$, current alcohol abuse, and current alcohol dependence among the three groups $\left(X^{2}\right.$ abuse $=2.177, X^{2}$ depedence $=2.198, P>$ 0.05). However, higher prevalence of lifetime alcohol use disorders was found in group with higher scores of CTQ $\left(X^{2}=9.315, P=0.009\right)$, emotional abuse $\left(X^{2}=8.025, P=0.018\right)$, physical abuse $\left(X^{2}=20.4080, P<0.001\right)$, but not in the group with higher scores of emotional neglect $\left(X^{2}=1.226, P=0.542\right)$, sexual abuse $\left(X^{2}=2.779, P=0.249\right)$, physical neglect $\left(X^{2}=3.978, P=0.137\right)$, LTE-Q $\left(X^{2}=5.415, P=0.067\right)$, and PSQI $\left(X^{2}=5.238, P=0.073\right)$. Protective factor for alcohol abuse for men was identified to be heavy drinking $(\mathrm{OR}=0.085,95 \% \mathrm{Cl}: 0.011-0.661)$, and the risk factors for alcohol abuse were identified to be frequent drinking ( $\mathrm{OR}=2.736,95 \% \mathrm{Cl}: 1.500,4.988)$, and consumption of low liquor $(\mathrm{OR}=2.563,95 \% \mathrm{Cl}: 1.387,4.734)$. Risk factors for alcohol dependence in males were identified to be consumption of low liquor $(\mathrm{OR}=5.501,95 \% \mathrm{Cl}: 2.004,15.103)$, frequent drinking $(\mathrm{OR}=2.680,95 \% \mathrm{Cl}: 1.164,6.170)$, and childhood physical abuse (OR $=2.310,95 \% \mathrm{Cl}: 1.026,5.201)$.

Conclusion: Traumatic experience during infant and prenatal periods does not have a strong statistical correlation with alcohol use disorders for male adults. However, subjects with high CTQ scores, experience of emotional abuse and physical abuse show a statistically higher prevalence of lifetime alcohol use disorders. Several risk factors including consumption of low liquor, frequent drinking, and childhood physical abuse contribute to alcohol dependence in male adults.

Keywords: Childhood trauma, Alcohol use disorder, Earthquake stress, Risk factor

\footnotetext{
* Correspondence: ydyywxy@163.com

${ }^{1}$ Department of Psychiatry, The First Hospital of Hebei Medical University, No.

89 Donggang Road, Shijiazhuang 050031, China

${ }^{2}$ The Mental Health Institute of Hebei Medical University, Shijiazhuang, China

Full list of author information is available at the end of the article
}

(c) The Author(s). 2020 Open Access This article is distributed under the terms of the Creative Commons Attribution 4.0 International License (http://creativecommons.org/licenses/by/4.0/), which permits unrestricted use, distribution, and reproduction in any medium, provided you give appropriate credit to the original author(s) and the source, provide a link to the Creative Commons license, and indicate if changes were made. The Creative Commons Public Domain Dedication waiver (http://creativecommons.org/publicdomain/zero/1.0/) applies to the data made available in this article, unless otherwise stated. 


\section{Background}

Alcohol dependence is a growing social epidemic around the world and it poses a significant threat to the well being of the affected individuals and the entire society [3, 4]. Specifically, alcohol addiction has not only led to a marked increase in social issues such as violent crime, traffic accidents and soaring divorce rates, but also caused a variety of psychological and physical diseases, producing a heavy burden on the health care system [5]. With the largest population in the world, China has witnessed a rapid growth of alcohol dependence prevalence from $0.4 \%$ in 1985 to $9 \%$ in 2009 [6]. The growing prevalence of alcohol dependence has attracted attention from scientific community seeking to unveil the underlying mechanism of alcohol dependence and address the need of effective alcohol addiction therapy [7]. The mechanism of alcohol use disorder is complicated and increasing evidence showed that stress is an important factor implicated in the pathological mechanism of alcohol dependence $[8,9]$. For example, Noori and $\mathrm{Yu}$ have performed rats foot shock and forced swim stress studies, showing stress can lead to increased alcohol intake and alcohol conditioned place preference [10,11]. In addition to the stress in adulthood, early life stress (ELS) is found to be related to alcohol dependence as well. Marinelli and co-workers confirmed that stress during the prenatal period is correlated to increased addiction risk during adulthood [12]. Further, it was found that maternal separation (MS) - a form of ELS - is a risk factor for binge drinking, and is linked to impulsivity, another key risk factor for excessive alcohol drinking in adulthood [13]. People with a history of childhood maltreatment, such as those in a war-exposed region for more than 30 days, showed 5.3 times higher chance of subsequent alcohol disorders compared to those not exposed [14]. It was hypothesized that the experience of ELS caused long-lasting modulation of neurons, as well as hyperactivity of the hypothalamuspituitary-adrenal (HPA) axis [15]. However, most research on the relationship between trauma and alcohol use disorders focus on a single age group, e.g., trauma happened during either childhood or adulthood [16, 17]. Furthermore, most of the previous studies on prenatal period stress are animal studies [18]. To the best of our knowledge, there are no reports on how the same ELS event affects individuals from different life stages (i.e., prenatal, infant, or childhood) and the direct comparison of the effect of a single ELS event on adulthood alcohol use disorder for different age groups. Therefore, we report herein our studies on the effects of a series of contributing factors - the 1976 Tangshan Earthquake, childhood traumatic experience, adulthood traumatic experience, and sleeping quality - on adulthood alcohol use disorder. We also aim to study the effects of Earthquake on alcohol use disorder for subjects who experienced the Earthquake at different stages of pregnancy (prenatal and infant) and present our analysis of the risk factors for adulthood alcohol use disorder with the same group of subjects.

\section{Methods \\ Subjects}

The subjects of this study were recruited from workers officially employed by the Kailuan Mining Group. Based on the dates of birth, the subjects were divided into three groups (from the eldest to the youngest): infant exposure group, prenatal exposure group, and nonexposure group.

The inclusion criteria for the infant exposure group included: 1) born and raised in Tangshan, 2) born between July 29, 1975 and April 28, 1976; 3) exposure to the earthquake at the age between 3 and 12 months.

The inclusion criteria for the prenatal exposure group included: 1) born and raised in Tangshan; 2) born between July 29, 1976 and April 28, 1977; 3) exposure to the earthquake during the prenatal period. Based on the age of the fetal when the mother was exposed to earthquake, this group was further divided into 3 subgroups: the first trimester group (1-3 months of mother's pregnancy during the earthquake), the second trimester group (4-6 months of mother's pregnancy during the earthquake), and the third trimester group (7-9 months of mother's pregnancy during the earthquake).

The inclusion criteria for the non-exposure group included: 1) born and raised in Tangshan; 2) born between July 29, 1977 and April 28, 1978; and 3) born 1-1.9 years after the earthquake.

The following exclusion criteria were applied: 1) mothers had infections, high blood pressure, epilepsy or seizures, diabetes, thyroid disease, or mental disorders during pregnancy [2]; mothers had history of drug use, drinking and poisoning during maternal or lactating period [3]; mother suffered from other traumatic events in addition to earthquake during pregnancy [4]; those who refused to participate in this study and did not sign the informed consent form.

\section{Methods}

This study is a cross-sectional study [19] and is approved by the Ethics Committee of the First Hospital of Hebei Medical University (No. 2014005). The research was registered at Chinese Clinical Trial Registry (No. ChiCTROOC-15006542). From January to December of 2014, 38 years after the earthquake, a total of 1534 eligible participants were recruited from Kailuan Mining Group. A total of 1325 subjects completed the study with a completion rate of $85.9 \%$. Each of the participants signed a written informed consent form. Standardized interviews and physical examinations are conducted by specially trained doctors in one-on-one interviews. 


\section{Collection of demographic information}

In brief, all participants underwent a physical examination and a standardized interview, which included questions about demographic information, the condition of mother during pregnancy (age at pregnancy, parity, etc.), the conditions of the babies (weight at birth), and smoking history, and family history of alcohol use disorder.

\section{Evaluation of alcohol use disorders}

Structured Clinical Interviews for DSM-IV Axis Disorders (patient version) (SCID) were performed on all subjects by psychiatrists for the diagnosis of alcohol use disorders according to literature protcols [20].

In addition to the diagnosis of lifetime/current alcohol dependence and lifetime/current alcohol abuse, the following information was also collected: self-reported use of alcohol, including frequency of drinking: drinking often currently ( $\geq 2$ times/week), used to drink often but do not drink currently (less than 1 time/year), drinking occasionally $(<2$ times/year), and no drinking history ( $\leq 1$ time/year); amount of alcohol consumed (according to the average daily alcohol consumption for men, binge is defined as drinking more than $90 \mathrm{~mL}$ of pure alcohol/ day, heavy drinking is defined as drinking more than 50 $\mathrm{mL}$ but less than $90 \mathrm{~mL}$ of alcohol/day, normal drinking is defined as drinking less than $50 \mathrm{~mL}$ of pure alcohol/ day); time of drinking; type of alcohol consumed: beer, red wine, low liquor $(<40 \%$ volume), high liquor $(\geq 40 \%$ volume).

\section{Childhood trauma}

Childhood trauma was assessed by childhood trauma questionnaire short form (CTQ-SF) [21], Chinese version, which is a retrospective self-report measurement with five dimensions: emotional abuse, physical abuse, sexual abuse, emotional neglect, and physical neglect. The scores obtained from five different dimensions were used to assess childhood experiences. The CTQ-SF has 28 entries in total, including 25 clinical items and 3 validation items. Each question starts with the sentence of "When I grew up and before I was 16 years old." The 20th question, for instance, was followed by, "somebody attempted to touch me or let me touch him in a sexual way." Based on the frequency of occurrence, the answer may be scored as follows: 1 point, never; 2 points, occasionally; 3 points, sometimes; 4 points, regular; 5 points, always. In the present study, for each dimension, the subtotal score was the sum of the score of each item that falls within that respective dimension, and the total score was the sum of the scores of the five dimensions [22]. Each of the five dimensions listed above is scored between 5 to 25 points, with a total score between 25 to 125 points.

\section{Adult trauma}

Adult trauma beginning at the age of 16 was evaluated by Lifetime of Experience Questionnaire (LTE-Q) [2]. With minor modifications to adapt to special circumstances in China, this questionnaire included questions on the following items [1]: loss of a spouse [2]; loss of parents and children [3]; economic difficulties [4]; divorce [5]; unemployment or layoff [6]; accidents (traffic accidents, fires, flooding, earthquake, or other natural disasters) [7]; incidents related to the crimes such as property loss, robbery, or kidnap [8]; others.

\section{Sleep quality}

Pittsburgh Sleep Quality Index (PSQI) [23], Chinese version, was calculated for the evaluation of sleep quality. The PSQI is composed of 19 self-assessments and 5 review questions, and only 18 self-assessment questions are scored. The sum of the score for each component is the PSQI total score, ranging from 0 to 21 . In general, score $\geq 7$ indicates sleep problems [24].

\section{Statistical analysis}

IBM SPSS version 22.0 was used for statistical analysis. The data is represented as the mean \pm standard deviation (SD). Chi-square tests were performed to compare the prevalence of alcohol use disorders among subjects categorized by various contributing factors listed above. Stepwise regression with forward selection approach was employed for method of analysis of all contributing factors. One-way ANOVA of variance or rank-sum test with multiple samples were performed for analysis of age and weight at birth. Multi-factor logistic regression was used to analyze risk factors for alcohol use disorders. A two-sided $P$-value $<0.05$ was considered statistically significant.

\section{Results \\ Baseline characteristics of study subjects}

1534 subjects met the inclusion criteria, but 129 of them did not participate in this study. As a result, we enrolled 1405 subjects for this study, of which 81 were excluded as shown in Fig. 1, leaving 1325 subjects on which statistical analysis was ultimately performed. As shown in Table 1, there is expected significant difference on the mean age of the three groups, namely, infant exposure, prenatal exposure, and non-exposure groups $(F=931.979, P<0.001)$. In particular, the mean age of these three groups differ by one year in the decreasing order. However, no significant difference among the three age groups is observed for gender $\left(X^{2}=0.786, P=0.675\right)$, education $\left(X^{2}=12.597, P=\right.$ $0.050)$, marital status $\left(X^{2}=2.976, P=0.812\right)$, smoke $\left(X^{2}=\right.$ 2.088, $P=0.719)$, mother's age at birth $(F=4.211, P=$ $0.122)$, parity $\left(X^{2}=1.226, P=0.874\right)$, birth weight $(F=$ 


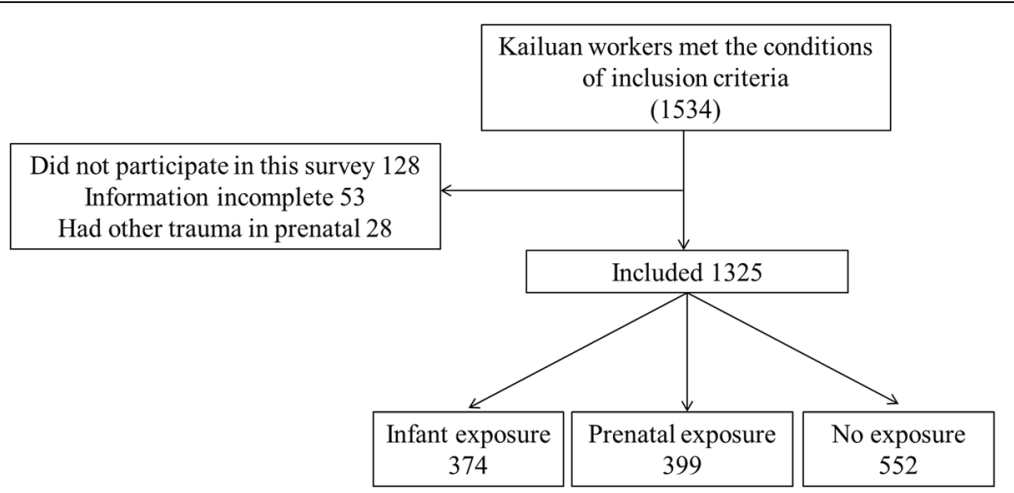

Fig. 1 The study follow chart

Table 1 Baseline characteristics of the subjects $(N=1325)$

\begin{tabular}{|c|c|c|c|c|c|c|}
\hline & & $\begin{array}{l}\text { Infant exposure } \\
\text { group }\end{array}$ & $\begin{array}{l}\text { Prenatal exposure } \\
\text { group }\end{array}$ & $\begin{array}{l}\text { No exposure } \\
\text { group }\end{array}$ & $\begin{array}{l}\text { Test } \\
\text { value }\end{array}$ & $P$ \\
\hline N & & 374 & 399 & 552 & & \\
\hline \multirow[t]{2}{*}{ Gender (\%) } & Male & $317(84.8)$ & $348(87.2)$ & $475(86.1)$ & \multirow[t]{2}{*}{0.786} & \multirow[t]{2}{*}{0.675} \\
\hline & Female & $57(15.2)$ & $51(12.8)$ & $77(13.9)$ & & \\
\hline Age (year) & & $39.5 \pm 0.6$ & $38.5 \pm 0.8$ & $37.5 \pm 0.9$ & 931.979 & $\begin{array}{l}< \\
0.001\end{array}$ \\
\hline \multirow[t]{4}{*}{ Education (\%) } & Illiterate and primary school & $9(2.4)$ & $8(2.0)$ & $6(1.1)$ & \multirow[t]{4}{*}{12.597} & \multirow[t]{4}{*}{0.05} \\
\hline & Junior high school & $70(18.7)$ & $64(16.0)$ & $73(13.2)$ & & \\
\hline & $\begin{array}{l}\text { High school / secondary } \\
\text { school }\end{array}$ & 197(52.7) & $221(55.4)$ & $289(52.4)$ & & \\
\hline & College and above & $98(26.2)$ & 106(26.6) & 184(33.3) & & \\
\hline \multirow[t]{4}{*}{ Marital status (\%) } & Unmarried & $4(1.1)$ & $7(1.8)$ & $3(0.5)$ & \multirow[t]{4}{*}{2.976} & \multirow[t]{4}{*}{0.812} \\
\hline & Married & $351(93.9)$ & $378(94.7)$ & 518(93.8) & & \\
\hline & Divorced & $16(4.3)$ & $17(4.3)$ & $29(5.3)$ & & \\
\hline & Widowed & $3(0.8)$ & $1(0.3)$ & $2(0.4)$ & & \\
\hline \multirow{5}{*}{$\begin{array}{l}\text { Average household income } \\
\text { (\%) }\end{array}$} & $\leq 1000 \mathrm{RMB}$ & $7(1.9)$ & $15(3.8)$ & $17(3.1)$ & \multirow[t]{5}{*}{7.397} & \multirow[t]{5}{*}{0.494} \\
\hline & $1001-2000 \mathrm{RMB}$ & $98(26.2)$ & $97(24.3)$ & $138(25.0)$ & & \\
\hline & 2001-5000RMB & $247(66.0)$ & $251(62.9)$ & $347(62.9)$ & & \\
\hline & 5001-10,000 RMB & $22(5.9)$ & $34(8.5)$ & $48(8.7)$ & & \\
\hline & $>10,000 \mathrm{RMB}$ & 0 & $2(0.5)$ & $2(0.4)$ & & \\
\hline \multirow[t]{3}{*}{ Smoke (\%) } & smoker & 182(48.7) & 195(48.9) & $280(50.7)$ & \multirow[t]{3}{*}{2.088} & \multirow[t]{3}{*}{0.719} \\
\hline & ex-smoker & $31(8.3)$ & $34(8.5)$ & $55(10.0)$ & & \\
\hline & Non-smoker & $161(43.0)$ & $170(42.6)$ & 217(39.3) & & \\
\hline \multicolumn{2}{|l|}{ N } & 374 & 399 & 552 & & \\
\hline \multicolumn{2}{|l|}{ Mother's age at birth } & $27.2 \pm 4.3$ & $27.4 \pm 4.9$ & $27.7 \pm 4.5$ & 4.211 & 0.122 \\
\hline \multirow[t]{3}{*}{ Parity (\%) } & First born & 196(52.4) & $208(52.1)$ & 269(48.7) & \multirow[t]{3}{*}{1.226} & \multirow[t]{3}{*}{0.874} \\
\hline & Second child & $99(26.5)$ & $110(27.6)$ & $133(24.1)$ & & \\
\hline & Other & $79(21.1)$ & $81(20.3)$ & $120(21.7)$ & & \\
\hline \multicolumn{2}{|l|}{ Birth weight (g) } & $3203.6 \pm 571.5$ & $3195.4 \pm 593.8$ & $3187.6 \pm 570.9$ & 0.066 & 0.936 \\
\hline \multicolumn{2}{|c|}{ Alcohol dependence family history (\%) } & $10(2.7)$ & $9(2.3)$ & $14(2.5)$ & 0.147 & 0.929 \\
\hline
\end{tabular}


Table 2 Prevalence of alcohol use disorder $(N=1325)$

\begin{tabular}{|c|c|c|c|c|c|c|}
\hline & & $\begin{array}{l}\text { Infant exposure } \\
\text { group }\end{array}$ & $\begin{array}{l}\text { Prenatal exposure } \\
\text { group }\end{array}$ & $\begin{array}{l}\text { Non-exposure } \\
\text { group }\end{array}$ & $\begin{array}{l}\text { Test } \\
\text { value }\end{array}$ & $P$ \\
\hline N & & 317 & 348 & 475 & & \\
\hline \multirow{3}{*}{$\begin{array}{l}\text { Alcohol use disorder for lifelong } \\
\text { diagnostics (\%) }\end{array}$} & No & 288(90.9) & $321(92.2)$ & $431(90.7)$ & \multirow[t]{3}{*}{4.480} & \multirow[t]{3}{*}{0.345} \\
\hline & Alcohol abuse & $14(4.4)$ & $16(4.6)$ & $31(6.5)$ & & \\
\hline & $\begin{array}{l}\text { Alcohol } \\
\text { dependence }\end{array}$ & $15(4.7)$ & $11(3.2)$ & $13(2.7)$ & & \\
\hline \multirow{2}{*}{$\begin{array}{l}\text { Alcohol use disorder for current diagnostics } \\
\text { (\%) }\end{array}$} & Alcohol abuse & $6(1.2)$ & $3(0.9)$ & $11(2.3)$ & 2.177 & 0.337 \\
\hline & $\begin{array}{l}\text { Alcohol } \\
\text { dependence }\end{array}$ & 10(3.2) & $9(2.6)$ & $7(1.5)$ & 2.098 & 0.350 \\
\hline
\end{tabular}

$0.066, P=0.936)$, and family history of alcohol dependence $\left(X^{2}=0.147, P=0.929\right)$.

\section{The prevalence of alcohol use disorders}

Since no diagnosis of lifetime alcohol abuse and alcohol dependence was observed for females, the following data analysis is based on male subjects only (See Table 2). Based on the results of chi-square test, there was no statistically significant difference among three age groups in the prevalence of subjects who are diagnosed with no alcohol use disorders $\left(X^{2}=4.480, P=0.345\right)$, as well as in the prevalence of subjects who are diagnosed of current alcohol abuse $\left(X^{2}=2.177, P=0.337\right)$ and current alcohol dependence $\left(X^{2}=2.098, P=0.350\right)$. The prevalence of lifetime alcohol dependence in infant exposure group, prenatal exposure group and non-exposure group was $4.7,3.2,2.7 \%$ respectively. The prevalence of lifetime or current alcohol abuse was substantially higher in the non-exposure group than that of the two exposure groups.

Further, when considering the prenatal exposure group alone, it was found that there was no statistically significant difference in the prevalence of lifelong diagnosis of alcohol use disorders among three subgroups of prenatal exposure group $\left(X^{2}=1.136, P=0.980\right)$. Similarly, there was not statistically significant difference in the prevalence of current diagnosis of alcohol abuse and dependence among three prenatal subgroups $\left(X_{\text {abuse }}^{2}=\right.$ $3.773, P_{\text {abuse }}=0.287 ; X_{\text {dependence }}^{2}=0.369, P_{\text {dependence }}=$ 0.947) (See Table 3).
Childhood, adulthood trauma and sleep quality

According to the scores of CTQ, LTE-Q, and PSQI, the subjects were categorized as high and low score subgroups. After chi-square test, it was found there was statistically significant difference in the prevalence of lifetime alcohol use disorders between the subgroups with high and low scores in CTQ $\left(X^{2}=9.315, P=0.009\right)$, emotional abuse $\left(X^{2}=8.025, P=0.018\right)$, physical abuse $\left(X^{2}=20.4080, P<0.001\right)$. However, no statistically significant difference was observed between the subgroups with high and low scores in emotional neglect $\left(X^{2}=\right.$ $1.226, P=0.542)$, sexual abuse $\left(X^{2}=2.779, P=0.249\right)$, physical neglect $\left(X^{2}=3.978, P=0.137\right)$, LTE-Q $\left(X^{2}=\right.$ 5.415, $P=0.067)$, and PSQI total scores $\left(X^{2}=5.238, P=\right.$ 0.073) (See Table 4).

\section{Drinking condition}

As shown in Table 5, statistically significant difference on the prevalence of lifetime alcohol use disorders was observed with different wine categories $\left(X^{2}=34.446, P<\right.$ 0.001), drinking frequency $\left(X^{2}=97.451, P<0.001\right)$, drinking time $\left(X^{2}=10.438, P=0.034\right)$, and alcohol consumption $\left(X^{2}=49.596, P<0.001\right)$.

\section{Risk factors for alcohol use disorders}

Logistic regression analysis was subsequently performed to identify risk factors for alcohol use disorders. As shown in Tables 6 and 7 , heavy drinking $(O R=5.679$, $95 \% \mathrm{CI}: 1.576,20.471)$ and frequency drinking (OR = 2.159, 95\%CI: $1.136,4.103)$ were identified to be the risk

Table 3 Prevalence of alcohol use disorder in different stages of pregnancy ( $N=348)$

\begin{tabular}{|c|c|c|c|c|c|c|}
\hline & & Early pregnancy & Mid-pregnancy & Late pregnancy & Test value & $P$ \\
\hline $\mathrm{N}$ & & 110 & 117 & 121 & & \\
\hline \multirow{3}{*}{$\begin{array}{l}\text { Alcohol use disorder for } \\
\text { lifelong diagnostics (\%) }\end{array}$} & No & 100(90.9) & 108(92.3) & $111(91.7)$ & 1.136 & 0.980 \\
\hline & Alcohol abuse & $5(4.5)$ & $5(4.3)$ & $6(5.0)$ & & \\
\hline & Alcohol dependence & $5(4.5)$ & $4(3.4)$ & $4(3.3)$ & & \\
\hline \multirow{2}{*}{$\begin{array}{l}\text { Alcohol use disorder for } \\
\text { current diagnostics (\%) }\end{array}$} & Alcohol abuse & 0 & $2(1.7)$ & $1(0.8)$ & 3.773 & 0.287 \\
\hline & Alcohol dependence & $3(2.7)$ & $3(2.6)$ & $3(2.4)$ & 0.369 & 0.947 \\
\hline
\end{tabular}


Table 4 Prevalence of alcohol use disorder for male subjects with high and low scores of CTQ, LTE-Q, and PSQI (N=1140)

\begin{tabular}{|c|c|c|c|c|c|c|}
\hline & & No & Alcohol abuse & Alcohol dependence & $x^{2}$ & $P$ \\
\hline N & & 1041 & 60 & 39 & & \\
\hline \multirow[t]{2}{*}{ CTQ total scores (\%) } & High & $369(88.7)$ & $24(5.8)$ & $23(5.5)$ & 9.315 & 0.009 \\
\hline & Low & 672(92.8) & $36(5.0)$ & $16(2.2)$ & & \\
\hline \multirow[t]{2}{*}{ Emotional abuse (\%) } & High & $320(88.4)$ & $22(6.1)$ & $20(5.5)$ & 8.025 & 0.018 \\
\hline & Low & $721(92.7)$ & $38(4.9)$ & $19(2.4)$ & & \\
\hline \multirow[t]{2}{*}{ Emotional neglect (\%) } & High & $364(90.5)$ & $21(5.2)$ & $17(4.2)$ & 1.226 & 0.542 \\
\hline & Low & $677(91.7)$ & $39(5.3)$ & $22(3.0)$ & & \\
\hline \multirow[t]{2}{*}{ Sexual abuse (\%) } & High & 164(89.6) & $9(4.9)$ & $10(5.5)$ & 2.779 & 0.249 \\
\hline & Low & 877(91.6) & $51(5.3)$ & $29(3.0)$ & & \\
\hline \multirow[t]{2}{*}{ Physical neglect (\%) } & High & $415(89.4)$ & $28(6.0)$ & $21(4.5)$ & 3.978 & 0.137 \\
\hline & Low & $626(92.6)$ & $32(4.7)$ & $18(2.7)$ & & \\
\hline \multirow[t]{2}{*}{ Physical abuse (\%) } & High & 185(85.3) & $14(6.5)$ & 18(8.3) & 20.408 & $<0.001$ \\
\hline & Low & 856(92.7) & $46(5.0)$ & $21(2.3)$ & & \\
\hline \multirow[t]{2}{*}{ LTE-Q total scores (\%) } & High & 392(90.7) & $19(4.4)$ & $21(4.9)$ & 5.415 & 0.067 \\
\hline & Low & $648(91.5)$ & $42(5.9)$ & $18(2.5)$ & & \\
\hline \multirow[t]{2}{*}{ PQSI total scores (\%) } & High & $171(87.2)$ & $15(7.7)$ & $10(5.1)$ & 5.238 & 0.073 \\
\hline & Low & $871(92.3)$ & $45(4.8)$ & $28(3.0)$ & & \\
\hline
\end{tabular}

(a) Low score is defined as $25-75$ and high score is defined as $76-125$

factors of alcohol abuse, and similar OR value after adjusting for age and education. For alcohol dependency, consumption of low liquor $(\mathrm{OR}=5.342,95 \% \mathrm{CI}$ : 1.842 , 15.495), frequent drinking $(\mathrm{OR}=2.957,95 \% \mathrm{CI}: 1.222$, 7.157), and childhood physical abuse (OR $=2.705,95 \%$ CI: $1.303,5.615)$ were identified as risk factors, and similar OR value after adjusting for age and education.

\section{Discussion}

Extensive studies have been done to investigate the relationship between different types of trauma and alcohol consumption, which consistently demonstrated increase of alcohol consumption one year or less after trauma [25-28]. For example, a study was conducted on the substance use following terrorist attack; in a follow-up

Table 5 Prevalence of alcohol use disorder for male subjects with different wine categories, drinking frequency, drinking years, and amount of alcohol consumption $(N=1140)$

\begin{tabular}{|c|c|c|c|c|c|c|}
\hline \multirow[b]{2}{*}{ N } & & \multirow{2}{*}{$\begin{array}{l}\text { No } \\
1036\end{array}$} & \multirow{2}{*}{$\begin{array}{l}\text { Alcohol abuse } \\
60\end{array}$} & \multirow{2}{*}{$\begin{array}{l}\text { Alcohol dependence } \\
39\end{array}$} & \multirow[t]{2}{*}{ Test value } & \multirow[t]{2}{*}{$P$} \\
\hline & & & & & & \\
\hline \multirow[t]{4}{*}{ Wine category (\%) } & Beer & $543(94.6)$ & $23(4.0)$ & $8(1.4)$ & 43.458 & $<0.001$ \\
\hline & Red wine & 10(90.9) & $1(9.1)$ & 0 & & \\
\hline & Low liquor & $400(82.5)$ & $46(9.5)$ & $39(8.0)$ & & \\
\hline & High liquor & 62(88.6) & $5(7.1)$ & $3(4.3)$ & & \\
\hline \multirow[t]{4}{*}{ Drinking frequency (\%) } & Frequently & 190(78.8) & $29(12.0)$ & $22(9.1)$ & 72.604 & $<0.001$ \\
\hline & Quit & $34(89.5)$ & $1(2.6)$ & $3(7.9)$ & & \\
\hline & Occasionally & $586(92.9)$ & $31(4.9)$ & $14(2.2)$ & & \\
\hline & No & 230(99.6) & $1(0.4)$ & 0 & & \\
\hline \multirow[t]{3}{*}{ Year of drinking (\%) } & $0-10$ & $557(90.3)$ & $41(6.6)$ & $19(3.1)$ & 13.775 & 0.008 \\
\hline & $11-20$ & $434(86.3)$ & $37(7.4)$ & $32(6.4)$ & & \\
\hline & $21-30$ & $14(70.0)$ & $4(20.0)$ & $2(10.0)$ & & \\
\hline \multirow{3}{*}{$\begin{array}{l}\text { Amount of alcohol } \\
\text { consumption (\%) }\end{array}$} & Normal & $980(92.1)$ & $57(5.4)$ & $27(2.5)$ & 40.428 & $<0.001$ \\
\hline & Heavy & 49(80.3) & $2(3.3)$ & $10(16.4)$ & & \\
\hline & Binge & $11(73.3)$ & $2(13.3)$ & $2(13.3)$ & & \\
\hline
\end{tabular}


Table 6 Multi-factor logistic regression analysis of risk factor for alcohol abuse $(N=1140)$

\begin{tabular}{|c|c|c|c|c|c|c|c|c|c|c|}
\hline & & $B$ & SE & wald & $P$ & OR & $95 \% \mathrm{Cl}$ & $\mathrm{aOR}$ & $P^{\prime}$ & $95 \% \mathrm{Cl}^{\prime}$ \\
\hline \multirow[t]{3}{*}{ Wine category } & High liquor & 0.141 & 0.687 & 0.042 & 0.837 & 1.152 & $(0.300,4.427)$ & 1.147 & 0.842 & $(0.298,4.410)$ \\
\hline & Low liquor & 0.606 & 0.349 & 3.009 & 0.083 & 1.833 & $(0.924,3.636)$ & 1.840 & 0.081 & $(0.928,3.648)$ \\
\hline & Beer and red wine & & & & & & & & & \\
\hline \multirow[t]{3}{*}{ Drinking frequency } & Frequently & 0.770 & 0.328 & 5.523 & 0.019 & 2.159 & $(1.136,4.103)$ & 2.180 & 0.017 & $(1.148,4.140)$ \\
\hline & Quit & -0.442 & 1.047 & 0.178 & 0.673 & 0.643 & $(0.083,5.002)$ & 0.643 & 0.673 & $(0.083,5.004)$ \\
\hline & Occasionally & & & & & & & & & \\
\hline \multirow{3}{*}{$\begin{array}{l}\text { Amount of alcohol } \\
\text { consumption }\end{array}$} & Binge & 1.041 & 0.698 & 2.225 & 0.136 & 2.833 & $(0.721,11.133)$ & 2.850 & 0.133 & $(0.726,11.192)$ \\
\hline & Heavy & 1.737 & 0.654 & 7.049 & 0.008 & 5.679 & $(1.576,20.471)$ & 5.756 & 0.007 & $(1.597,20.748)$ \\
\hline & Normal & & & & & & & & & \\
\hline \multirow[t]{2}{*}{ Physical abuse } & High & 0.408 & 0.336 & 1.478 & 0.224 & 1.504 & $(0.779,2.904)$ & 1.495 & 0.231 & $(0.774,2.888)$ \\
\hline & Low & & & & & & & & & \\
\hline
\end{tabular}

Note: Forward stepwise logistic regression method was employed. aOR values are generated by taking into account age and education as covariance and were then adjusted for these two factors. $\mathrm{P}^{\prime}$ and $95 \% \mathrm{Cl}^{\prime}$ are values after adjustment

period ranging from 1 week to more than 2 years, it was found that $7.3 \%$ (95\% CI: $1.1-32.5 \%$ ) of the population with pre-existing alcohol use conditions reported increased alcohol consumption in the first 2 years following a terrorist event [29]. However, it is important to note that there was no new occurrences (new since the terrorist event) of alcohol use disorders observed after terrorist events [30]. Moreover, a study documented that after exposures to trauma such as floods, guns, plane crashes, etc., only $0.3 \%$ of the sample developed an acute new post-trauma alcohol use disorder [31]. Therefore, it is believed that the vast majority of post-trauma alcohol use disorders represented the continuation or recurrence of pre-existing conditions.

Long-term increases of alcohol consumption after ELS [32] has been well documented. For instance, Gondré-Lewis et al. demonstrated that ELS is as a risk factor for alcohol consumption and abuse in adulthood, such as binge drinking and impulsive-like behavior, acting through a CRF/
$\mathrm{GABA}_{\mathrm{A}}$ mechanism [13]. Consistent with previous studies, our study showed that there is a slightly increased prevalence of the lifetime or current alcohol use disorder in prenatal and infant exposure group compared to non-exposure group of the earthquake, although the difference among these age groups is not statistically significant. Similarly, there was no statistically significant difference in the prevalence of male alcohol use disorders for subgroups that are exposed to earthquake at different stages of pregnancy. It is important to mention that previous studies with extended follow-up periods showed that the effect of ELS on alcohol use disorder generally attenuates over time (6 months vs. 30 months) [28]. Given the fact that the assessment of alcohol use disorder was performed 38 years after the traumatic event, the attenuation effect for the present study is likely to be even more significant.

It has been increasingly evident that traumatic events in childhood contribute to subsequent psychopathology of mental health including alcohol use disorder [14, 33-

Table 7 Multi-factor logistic regression of risk factor for alcohol dependence $(N=1140)$

\begin{tabular}{|c|c|c|c|c|c|c|c|c|c|c|}
\hline & & B & SE & wald & $P$ & OR & $95 \% \mathrm{Cl}$ & $\mathrm{aOR}$ & $P^{\prime}$ & $95 \% \mathrm{Cl}^{\prime}$ \\
\hline \multirow[t]{3}{*}{ Wine category } & High liquor & 0.423 & 0.914 & 0.215 & 0.643 & 1.527 & $(0.255,9.154)$ & 1.526 & 0.644 & $(0.255,9.154)$ \\
\hline & Low liquor & 1.676 & 0.543 & 9.510 & 0.002 & 5.342 & $(1.842,15.495)$ & 5.352 & 0.002 & $(1.845,15.521)$ \\
\hline & Beer and red wine & & & & & & & & & \\
\hline \multirow[t]{3}{*}{ Drinking frequency } & Frequently & 1.084 & 0.451 & 5.779 & 0.016 & 2.957 & $(1.222,7.157)$ & 2.977 & 0.015 & $(1.231,7.202)$ \\
\hline & Quit & 0.123 & 1.083 & 0.013 & 0.909 & 1.131 & $(0.135,9.450)$ & 1.133 & 0.908 & $(0.136,9.460)$ \\
\hline & Occasionally & & & & & & & & & \\
\hline \multirow[t]{3}{*}{ Amount of alcohol consumption } & Binge & -0.314 & 0.557 & 0.317 & 0.573 & 0.731 & $(0.245,2.176)$ & 0.734 & 0.578 & $(0.247,2.183)$ \\
\hline & Heavy & -0.423 & 0.506 & 0.698 & 0.403 & 0.655 & $(0.243,1.767)$ & 0.664 & 0.419 & $(0.246,1.792)$ \\
\hline & Normal & & & & & & & & & \\
\hline \multirow[t]{2}{*}{ Physical abuse } & High & 0.995 & 0.373 & 7.126 & 0.008 & 2.705 & $(1.303,5.615)$ & 2.692 & 0.008 & $(1.297,5.589)$ \\
\hline & Low & & & & & & & & & \\
\hline
\end{tabular}


36]. Most forms of child maltreatment are related to higher risk of adolescent alcohol consumption [37] and adult alcohol consumption and alcohol disorders [38, 39]. For example, Evren and co-workers have demonstrated that childhood traumatic experience, especially those related to emotional abuse, e.g., disassociation, might be a mediating factor that contributes to the development of lifetime traumatic stress disorder (PTSD) and alcohol dependence $[40,41]$. Additionally, the data obtained from a study on a pair of twins showed individuals exposed to childhood maltreatment were 1.74 times more likely to experience alcohol use disorder in adulthood [42]. Bulik et al. suggested that the early life adversity may influence the development of adolescent brain in specific regions, such as slowing down the development of the hippocampus [43]. Among the early life adversities, our study showed that the childhood physical abuse $(\mathrm{OR}=2.310$, $95 \%$ CI: $1.026,5.201)$ is one of the risk factors for male alcohol dependence. The physical abuse in childhood may lead to emotion regulation difficulties, which may play a significant role in alcohol use disorder [44]. With respect to the childhood sexual abuse, our study showed that there does not appear to be a strong correlation between childhood sexual abuse and alcohol use disorder in adulthood. Moreover, Bulik's study on adult female twins also indicated no correlation between childhood sexual abuse and alcohol use disorders [43]. In contrast, another study based on retrospective assessment of childhood sexual abuse showed significantly increased chance of alcohol disorders [45]. The discrepancy on the role of early age sexual abuse plays in adulthood alcohol use is probably attributed to the difference in the selection of samples. For our study, this is also likely because childhood sexual abuse was rare in China in the 1970s.

The present work provides a comprehensive analysis on the effect of single traumatic event on individuals from different age groups and sheds light on the underlying risk factors for adulthood alcohol use disorder. However, since this study is conducted on a retrospective and selfassessment basis and a dynamic evaluation of the individual's alcohol use shortly after trauma is lacking. It was difficult to obtain a baseline of the individual's predisposition to alcohol use disorders 38 years after the earthquake. Further, as the prevalence of female alcohol dependence in the general population of China is only $0.09 \%$ [46], and there are fewer females in this study (about 50 in each group), we only analyzed data of male subjects. Future work employing a larger sample size for the investigation of women's alcohol dependence after trauma is well underway.

\section{Conclusion}

Our results suggest traumatic experience during infant and prenatal periods does not have a strong correlation with alcohol use disorders for male adults. Additionally, exposure to traumatic event during different stages of pregnancy does not affect the likelihood of adulthood alcohol use disorder. Furthermore, we identified that the consumption of low concentration liquor and frequent drinking, as well as childhood physical abuse are risk factors for alcohol dependence in male adults. The present study provides valuable insights into the correlation between alcohol use disorder and childhood trauma, and may offer guidance for alcohol use disorder therapy.

\section{Abbreviations}

CTQ-SF: The childhood trauma questionnaire short form; ELS: Early life stress; HPA: Hypothalamuspituitary-adrenal; LTE-Q: Lifetime of Experience

Questionnaire; MS: Maternal separation; SCID: Structured Clinical Interviews for DSM-IV Axis Disorders (patient version); SD: Standard deviation

\section{Acknowledgements}

None.

\section{Authors' contributions}

X-Y W conceived and designed the experiments; LW, C-X A, MS, NL, Y-Y G, $X-C Z, L-L Y$, and $Y-M W$ performed the research; $L W$ conducted the data analysis and wrote the manuscript and X-Y W Wang revised the manuscript. All authors read and approved the final manuscript.

\section{Funding}

This work was supported by the National Natural Science Foundation of China (No. 81271489), Natural Science Foundation of Hebei Province (No. H2015206392), Government Sponsored Provincial Clinical Medicine Talents Program (No. LS201605) and Major medical research projects from Health Commission of Hebei Province (No. zd2013085). The funders have no roles in the design of the study, the collection, analysis, and interpretation of data and in writing the manuscript.

\section{Availability of data and materials}

The datasets generated and analyzed during the current study are available from the corresponding author on reasonable request.

Ethics approval and consent to participate

The study protocol was approved by the Ethics Committee of the First Hospital of Hebei Medical University (Approval number: 20140005). Written Informed consent to participate was obtained from all the study subjects before enrollment

Consent for publication

Not Applicable.

\section{Competing interests}

The authors declare that they have no competing interests.

\section{Author details}

${ }^{1}$ Department of Psychiatry, The First Hospital of Hebei Medical University, No. 89 Donggang Road, Shijiazhuang 050031, China. ${ }^{2}$ The Mental Health Institute of Hebei Medical University, Shijiazhuang, China. ${ }^{3}$ Hebei Brain Ageing and

Cognitive Neuroscience Laboratory, Shijiazhuang, China.

Received: 26 January 2019 Accepted: 2 January 2020

Published online: 09 January 2020

\section{References}

1. He J, Zhong X, Gao Y, Xiong G, Yao S. Psychometric properties of the Chinese version of the childhood trauma questionnaire-short form (CTQ-SF) among undergraduates and depressive patients. Child Abuse Negl. 2019;91:102-8.

2. Brugha TS, Cragg D. The list of threatening experiences: the reliability and validity of a brief life events questionnaire. Acta Psychiatr Scand. 1990;82(1):77-81. 
3. Schomerus $\mathrm{G}$, Lucht M, Holzinger A, Matschinger H, Carta MG, Angermeyer MC. The stigma of alcohol dependence compared with other mental disorders: a review of population studies. Alcohol Alcohol. 2010;46(2):105-12.

4. Skinner HA, Allen BA. Alcohol dependence syndrome: measurement and validation. J Abnorm Psychol. 1982;91(3):199.

5. Edwards G, Gross MM. Alcohol dependence: provisional description of a clinical syndrome. Br Med J. 1976;1(6017):1058.

6. Phillips MR, Zhang J, Shi Q, et al. Prevalence, treatment, and associated disability of mental disorders in four provinces in China during 2001-05: an epidemiological survey. Lancet. 2009;373(9680):2041-53.

7. Littleton JM. Acamprosate in alcohol dependence: implications of a unique mechanism of action. J Addict Med. 2007;1(3):115-25.

8. Cooper ML, Russell M, Skinner JB, Frone MR, Mudar P. Stress and alcohol use: moderating effects of gender, coping, and alcohol expectancies. J Abnorm Psychol. 1992:101(1):139.

9. Smith LJ, Gallagher MW, Tran JK, Vujanovic AA. Posttraumatic stress, alcohol use, and alcohol use reasons in firefighters: the role of sleep disturbance. Compr Psychiatry. 2018;87:64-71.

10. Noori HR, Helinski S, Spanagel R. Cluster and meta-analyses on factors influencing stress-induced alcohol drinking and relapse in rodents. Addict Biol. 2014;19(2):225-32.

11. Yu L, Wang $L$, Zhao $X$, Song $M$, Wang $X$. Role of single prolonged stress in acquisition of alcohol conditioned place preference in rats. Life Sci. 2016; 151:259-63.

12. Marinelli M, Piazza PV. Interaction between glucocorticoid hormones, stress and psychostimulant drugs. Eur J Neurosci. 2002;16(3):387-94.

13. Gondr $\tilde{A}$-Lewis MC, Warnock KT, Hong W, et al. Early life stress is a risk factor for excessive alcohol drinking and impulsivity in adults and is mediated via a CRF/GABAA mechanism. Stress. 2016;19(2):1-13.

14. Keyes KM, Shmulewitz D, Greenstein E, et al. Exposure to the Lebanon war of 2006 and effects on alcohol use disorders: the moderating role of childhood maltreatment. Drug Alcohol Depend. 2014;139(1):296.

15. Koe AS, Salzberg MR, Morris MJ, Obrien TJ, Jones NC. Early life maternal separation stress augmentation of limbic epileptogenesis: the role of corticosterone and HPA axis programming. Psychoneuroendocrinology. 2014;42(2):124.

16. Keyes KM, Hatzenbuehler ML, Hasin DS. Stressful life experiences, alcohol consumption, and alcohol use disorders: the epidemiologic evidence for four main types of stressors. Psychopharmacology. 2011;218(1):1.

17. Ertl V, Saile R, Neuner F, Catani C. Drinking to ease the burden: a crosssectional study on trauma, alcohol abuse and psychopathology in a postconflict context. BMC Psychiatry. 2016;16(1):202.

18. Bell RL, Lopez MF, Cui C, et al. Ibudilast reduces alcohol drinking in multiple animal models of alcohol dependence. Addict Biol. 2015;20(1):38-42.

19. Li N, Wang $Y$, Zhao $X$, et al. Long-term effect of early-life stress from earthquake exposure on working memory in adulthood. Neuropsychiatr Dis Treat. 2015;11(default):2959-65.

20. Ray LA, Kahler CW, Young D, Chelminski I, Zimmerman M. The factor structure and severity of DSM-IV alcohol abuse and dependence symptoms in psychiatric outpatients. J Stud Alcohol Drugs. 2008;69(4):496-9.

21. Jiang WJ, Zhong BL, Liu LZ, Zhou YJ, Hu XH, Li Y. Reliability and validity of the Chinese version of the childhood trauma questionnaire-short form for inpatients with schizophrenia. PLoS One. 2018;13(12):e0208779.

22. Zhao XF, Zhang YL, Li LF, et al. Reliability and validity of the Chinese version of childhood trauma questionnaire. Chinese J Clin Rehab. 2005;9(20):105-7.

23. Woo J, Hong A, Lau E, Lynn H. A randomised controlled trial of tai chi and resistance exercise on bone health, muscle strength and balance in community-living elderly people. Age Ageing. 2007;36(3):262.

24. Liu XC, Tang MQ. Reliability and validity of the Pittsburgh sleep quality index. Chinese J Psychiatry. 1996.

25. Sims A, Sims D. The phenomenology of post-traumatic stress disorder. Psychopathology. 1998;31(2):96-112.

26. Reijneveld SA, Crone MR, Verhulst FC, Verloove-Vanhorick SP. The effect of a severe disaster on the mental health of adolescents: a controlled study. Lancet (London, England). 2003;362(9385):691-6.

27. Kohn R, Levav I, Garcia ID, Machuca ME, Tamashiro R. Prevalence, risk factors and aging vulnerability for psychopathology following a natural disaster in a developing country. Int J Geriatr Psychiatry. 2005;20(9):835-41.

28. Joseph S, Yule W, Williams R, Hodgkinson P. Increased substance use in survivors of the herald of free Enterprise disaster. Br J Med Psychol. 1993; 66(2):185-91.
29. Dimaggio C, Galea S, Li G. Substance use and misuse in the aftermath of terrorism. A Bayesian meta-analysis. Addiction (Abingdon, England). 2009; 104(6):894-904.

30. North CS, Pfefferbaum B, Narayanan P, et al. Comparison of post-disaster psychiatric disorders after terrorist bombings in Nairobi and Oklahoma City. Br J Psychiatry. 2005;186(3):487-93.

31. North CS, Ringwalt CL, Downs D, Derzon J, Galvin D. Postdisaster course of alcohol use disorders in systematically studied survivors of 10 disasters. Arch Gen Psychiatry. 2011;68(2):173-80.

32. Cruz FC, Quadros IM, Planeta CDS, Miczek KA. Maternal separation stress in male mice: long-term increases in alcohol intake. Psychopharmacology. 2008;201 (3):459

33. Keyes KM, Eaton NR, Krueger RF, et al. Childhood maltreatment and the structure of common psychiatric disorders. Br J Psychiatry. 2012;200(2):107.

34. Schiff M, Benbenishty R, Mckay M, Devoe E, Liu X, Hasin D. Exposure to terrorism and Israeli Youths' psychological distress and alcohol use: an exploratory study. Am J Addict. 2006;15(3):220-6.

35. Waldrop AE, Santa Ana EJ, Saladin ME, McRae AL, Brady KT. Differences in early onset alcohol use and heavy drinking among persons with childhood and adulthood trauma. Am J Addict. 2007;16(6):439-42.

36. Walsh $\mathrm{K}$, Latzman NE, Latzman RD. Pathway from child sexual and physical abuse to risky sex among emerging adults: the role of trauma-related intrusions and alcohol problems. J Adolesc Health. 2014;54(4):442-8.

37. Hussey JM, Chang JJ, Kotch JB. Child maltreatment in the United States: prevalence, risk factors, and adolescent health consequences. Pediatrics. 2006;118(3):933-42.

38. Anda RF, Whitfield CL, Felitti VJ, et al. Adverse childhood experiences, alcoholic parents, and later risk of alcoholism and depression. Psychiatr Serv. 2002:53(8):1001-9.

39. Nelson EC, Heath AC, Lynskey MT, et al. Childhood sexual abuse and risks for licit and illicit drug-related outcomes: a twin study. Psychol Med. 2006; 36(10):1473-83.

40. Evren C, Sar V, Dalbudak E, et al. Lifetime PTSD and quality of life among alcohol-dependent men: impact of childhood emotional abuse and dissociation. Psychiatry Res. 2011;186(1):85-90.

41. Evren C, Umut G, Bozkurt M, Evren B, Agachanli R. Mediating role of childhood emotional abuse on the relationship between severity of ADHD and PTSD symptoms in a sample of male inpatients with alcohol use disorder. Psychiatry Res. 2016;239:320-4.

42. Youngwolff KC, Kendler KS, Ericson ML, Prescott CA. Accounting for the association between childhood maltreatment and alcohol-use disorders in males: a twin study. Psychol Med. 2011;41(1):59.

43. Bulik CM, Prescott CA, Kendler KS. Features of childhood sexual abuse and the development of psychiatric and substance use disorders. Br J Psychiatry. 2001;179(9):444

44. Dutcher CD, Vujanovic AA, Paulus DJ, Bartlett BA. Childhood maltreatment severity and alcohol use in adult psychiatric inpatients: the mediating role of emotion regulation difficulties. Gen Hosp Psychiatry. 2017:42-50.

45. Nelson EC, Heath AC, Madden PA, et al. Association between self-reported childhood sexual abuse and adverse psychosocial outcomes: results from a twin study. Arch Gen Psychiatry. 2002;59(2):139.

46. Phillips MR, Zhang JX, Shi QC, et al. Prevalence, treatment, and associated disability of mental disorders in four provinces in China during 2001-05: an epidemiological survey. Lancet (London, England). 2009;373(9680):2041.

\section{Publisher's Note}

Springer Nature remains neutral with regard to jurisdictional claims in published maps and institutional affiliations. 